\title{
O filho com transtorno global do desenvolvimento: percepções de mães acerca de cuidados cotidianos
}

\section{The son with pervasive developmental disorder: the mothers' perception of daily care El hijo con transtorno generalizado del desarrollo: percepción de las madres a cerca de cuidados diários}

Recebido: 19/12/2015

Aprovado: 03/04/2016

Publicado: 01/05/2016

\author{
Chalimar da Cunha ${ }^{1}$ \\ Raquel Godinho Hokama Santos ${ }^{2}$ \\ Diene Monique Carlos ${ }^{3}$
}

O objetivo deste estudo foi conhecer e analisar a percepção de mães sobre o cuidado e as demandas de cuidado do filho com Transtorno Global do Desenvolvimento (TGD). Pesquisa qualitativa, sendo a coleta de dados realizada através de entrevistas semiestruturadas com sete mães, e a análise através do método de análise de conteúdo, modalidade temática. Emergiram dois núcleos temáticos intitulados Diferença; e Cuidado e Sobrecarga versus Proteção. Evidenciou-se que as mães percebem as alterações apresentadas por seus filhos a partir da comparação com outras crianças, e principalmente no âmbito da interação social. A sobrecarga pelos cuidados intensivos com os filhos é ressaltada, e os percebem como extremamente frágeis, reforçando a necessidade de proteção sobre eles. São necessárias ações dirigidas a mães de crianças e adolescentes com TGD, principalmente na organização do processo de avaliação dos transtornos mentais e no processo de adaptação pessoal e social frente às alterações vivenciadas.

Descritores: Mães; Saúde mental; Criança; Adolescente; Enfermagem.

The objective of this study was to understand and analyze the mother's perception on the care and care demands by the sons with Pervasive Developmental Disorder (PDD). Qualitative research, with data collection conducted through semi-structured interviews with seven mothers and analysis through content analysis method, thematic modality. Two core themes emerged, and they were entitled Difference; and Care and Overload versus Protection. It showed that mothers perceive the changes by their children from the comparison with other children, especially in the context of social interaction. The overload for children' intensive care is emphasized, and they perceived them as extremely fragile, reinforcing the need for protection. Actions are required with mothers of children and adolescents with PDD, especially in the organization of the evaluation process of mental disorders and the process of personal and social adjustment in the face of changes experienced.

Descriptors: Mothers; Mental health; Child; Adolescent; Nursing.

El objetivo de este estudio fue conocer y analizar la percepción de las madres sobre las demandas de atención y cuidado de niños con Trastorno Global del Desarrollo (TGD). Investigación cualitativa, con la recogida de datos realizada a través de entrevistas semiestructuradas con siete madres, y el análisis a través del método de análisis de contenido, modalidad temática. Surgieron dos temas centrales Diferencia; y Cuidado y Sobrecarga versus Protección. Se demostró que las madres perciben los cambios de sus hijos por la comparación con otros niños, especialmente en el contexto de la interacción social. La sobrecarga de cuidados intensivos de los niños fue apuntada, y estos son percibidos como extremadamente frágiles, lo que refuerza la necesidad de protección en ellos. Si requieren acciones dirigidas a las madres de niños y adolescentes con TGD, especialmente en la organización del proceso de evaluación de los trastornos mentales y el proceso de ajuste personal y social en la función de los cambios experimentados.

Descriptores: Madres; Salud mental; Niño; Adolescente; Enfermería.

${ }^{1}$ Enfermeira. Especialista em Gerenciamento dos Serviços em Enfermagem e em Educação. Docente e Responsável Técnica do curso Técnico em Enfermagem do SENAC-Unidade Santo Amaro, SP, Brasil. claudia.cmsantos@sp.senac.br.Brasil.

2 Enfermeira. Mestre e Doutora em Enfermagem na Saúde do Adulto. Pós Doutora em Enfermagem. Docente do Curso de Mestrado em Enfermagem da Universidade de Guarulhos. Professora Adjunta da Faculdade de Medicina de Jundiaí SP, Brasil. apuggina@prof.ung.br. Brasil.

${ }^{3}$ Enfermeira. Mestre e Doutora em Enfermagem. Docente do Curso de Mestrado em Enfermagem da Universidade de Guarulhos. Reitora da Universidade de Guarulhos, SP, Brasil. lucianeluciopereira@gmail.com. Brasil. 


\section{INTRODUÇÃO}

$\mathrm{A}$ família, diante de um diagnóstico de transtorno físico ou mental em seus filhos, inicia um difícil processo de adaptação, sendo que muitas vezes precisa repensar a sua estrutura e forma organizacional enquanto grupo, porque o cuidado à criança portadora deste transtorno exige presença constante de um cuidador, que geralmente é a mãe $\mathrm{e}^{1,2}$.

É reconhecido que desde o momento em que se descobre a gravidez, pais e mães começam a fazer planos quanto ao futuro do filho e dificilmente pensam na possibilidade de vir a ter um bebê com qualquer desvio da "normalidade". A gravidez e o nascimento geralmente são acompanhados de comemoração e de expectativas, e qualquer eventualidade desconhecida ou não planejada pode ser uma realidade difícil de ser assimilada ${ }^{2}$. Entende-se que, em todas as famílias, em maior ou menor grau, tais expectativas necessitam ser reelaboradas, pois certamente a criança frustrará, em algum aspecto, a idealização dos pais ${ }^{3}$.

Neste estudo, será abordado um transtorno mental específico - o transtorno global do desenvolvimento (TGD). Segundo a Classificação Estatística Internacional de Doenças e Problemas relacionados à Saúde 10 a revisão (CID - 10) o TGD se caracteriza por um grupo de distúrbios (entre eles o autismo) que apresenta comprometimento em três áreas do desenvolvimento principais - habilidades de interação social; comunicação; e comportamentos e interesses repetitivos e restritos.

Pode trazer como manifestações a invariância de hábitos e comportamentos ritualísticos, além de frequentes crises de birra, autoagressividade, alterações no sono e alimentação, ausência de noções de perigo, hipo ou hiper-reações a estímulos sensoriais como luz ou sons, apego a itinerários. A criança com esta síndrome geralmente não estabelece contatos físicos, visuais ou auditivos, e nem tão pouco afetivos ${ }^{4,5}$.

0 cuidador, que frequentemente é a mãe, e as famílias podem vivenciar grandes desconfortos e sofrimentos, bem como frustrações, principalmente pelo fato de alguns destes indivíduos apresentarem dificuldades para estabelecerem contatos afetivos $^{2,6}$. Tais impactos são percebidos pelas pessoas mais próximas, e que estão envolvidas diretamente nos seus cuidados e atividades diárias ${ }^{4,5}$.

Estudos vêm discutindo a rede e apoio social às famílias de crianças e adolescentes com condições crônicas de saúde, assim como o olhar das famílias frente ao cuidado neste âmbito ${ }^{2,7-9}$. Entretanto, são perceptíveis algumas lacunas, e este estudo se norteou pela seguinte questão: Quais os cuidados e demandas de cuidado de crianças e adolescentes com TGD, sob a ótica das mães? Tal aspecto, em especial para a Enfermagem, área que ainda se mostra incipiente nesta discussão ${ }^{10}$, se coloca como primordial para a construção de um cuidado mais coerente às necessidades destas famílias. Nessa perspectiva, o objetivo desta pesquisa é conhecer e analisar a percepção de mães sobre o cuidado e as demandas de cuidado do filho com TGD.

\section{MÉTODO}

A pesquisa possui abordagem qualitativa, e trata-se de estudo descritivo e exploratório, realizado em um Centro de Atenção Psicossocial infanto-juvenil (CAPSi) de um município do interior do estado de São Paulo, responsável pelo atendimento de crianças e adolescentes com transtornos mentais graves e suas famílias.

As participantes foram sete mães de crianças e adolescentes com hipótese diagnóstica de TGD, conforme registrado em prontuário pela equipe do CAPSi. A amostra de conveniência foi composta a partir dos seguintes critérios: (i) considerar apenas as mães que possuem pelo menos um filho, sendo criança ou adolescente, com hipótese diagnóstica de TGD; (ii) considerar apenas as mães de crianças e adolescentes que receberam a hipótese diagnóstica e iniciaram o acompanhamento no serviço estudado com tempo superior a 6 meses ao início da coleta de dados; (iii) considerar tais sujeitos em número suficiente para que se possa ter reincidência das informações; (iv) considerar a possibilidade de inclusões sucessivas de 
sujeitos até que seja possível uma discussão densa das questões da pesquisa.

A coordenação do serviço forneceu uma lista com nove mães que correspondiam a estes critérios, sendo que se atingiu a saturação dos dados com sete delas.

A coleta de dados junto às mães se deu a partir de entrevistas semiestruturadas conduzidas por um roteiro que permitiu explorar dados relativos ao entendimento das mães sobre o diagnóstico e o atendimento de seus filhos; as dificuldades de cada mãe para lidar com seus filhos; os fatores que as auxiliavam a lidar com as situações vividas junto aos filhos. 0 roteiro previamente definido possuía questões abertas e norteadoras.

Previamente à coleta de dados, o projeto de pesquisa foi aprovado pelo Comitê de Ética em Pesquisa da Faculdade de Medicina de Jundiaí (CEP-FMJ), em 14 de setembro de 2011, protocolo $\mathrm{n}^{\circ}$ 228/2011. Após esta aprovação, foi solicitada autorização à coordenação do serviço em questão, e ainda conforme a Resolução $\mathrm{n}^{\mathrm{o}}$ 196/96 do Conselho Nacional de Saúde, os sujeitos que concordaram em participar do estudo assinaram o Termo de Consentimento Livre e Esclarecido.

Inicialmente, em maio de 2011, foram realizadas visitas ao campo de estudo para se promover aproximação com o serviço, conhecer os profissionais envolvidos e suas propostas para a dinâmica de atendimentos, visando criar vínculo com o local para posterior realização da coleta de dados.

Em setembro de 2011 se iniciou a coleta de dados com as mães, após contato telefônico prévio e agendamento das entrevistas, que foram realizadas no próprio serviço de saúde, e tiveram duração média de 50 minutos; foram gravadas em aparelho MP4 após orientação e explicação sobre o objetivo da pesquisa e consentimento das mães. Para garantir o sigilo das informações e anonimato das participantes, se utilizou nomes fictícios para identificar as entrevistas (nomes de flores) e os nomes próprios citados durante as entrevistas foram identificados com suas iniciais.

Os dados coletados foram analisados a partir do método de análise de conteúdo, modalidade temática ${ }^{11}$. Para a operacionalização desta proposta, seguiramse as etapas: pré-análise; exploração do material; tratamento dos resultados e interpretação.

\section{RESULTADOS}

A Tabela 1 traz as características principais dos participantes no estudo. A partir da análise dos dados, emergiram duas categorias temáticas intituladas: Diferença; e, Cuidado: sobrecarga versus proteção.

Tabela 1. Sujeitos do estudo segundo hipótese diagnóstica, idade e sexo dos filhos, número de filhos, origem do encaminhamento e tempo de tratamento no CAPSi. São Paulo, 2011.

\begin{tabular}{|c|c|c|c|c|}
\hline Mães & $\begin{array}{c}\text { Hipótese } \\
\text { Diagnóstica }\end{array}$ & $\begin{array}{l}\text { Idade Sexo } \\
\text { Filhos(as) }\end{array}$ & $\begin{array}{c}\text { Origem do } \\
\text { Encaminhamento }\end{array}$ & $\begin{array}{c}\text { Tempo de } \\
\text { Tratamento } \\
\text { no CAPSi }\end{array}$ \\
\hline $\begin{array}{c}\text { (E1) } \\
\text { Azaléia }\end{array}$ & $\begin{array}{l}\text { Síndrome de } \\
\text { Asperger }\end{array}$ & $\begin{array}{c}14 \text { anos } \\
\mathrm{M}\end{array}$ & Centro de Reabilitação & 4 anos \\
\hline $\begin{array}{c}\text { (E2) } \\
\text { Hortência }\end{array}$ & $\begin{array}{l}\text { Síndrome de } \\
\text { Asperger }\end{array}$ & $\begin{array}{c}10 \text { anos } \\
\mathrm{M}\end{array}$ & Núcleo Integrado de Saúde & 2 anos \\
\hline $\begin{array}{c}\text { (E3) } \\
\text { Camélia }\end{array}$ & $\begin{array}{c}\text { Alteração de } \\
\text { comporta/o } \\
\text { compatível à TGD }\end{array}$ & $\begin{array}{c}10 \text { anos } \\
\mathrm{F}\end{array}$ & $\begin{array}{c}\text { Associação Terapêutica de } \\
\text { Estimulação Auditiva e } \\
\text { Linguagem }\end{array}$ & 8 meses \\
\hline $\begin{array}{c}\text { (E4) } \\
\text { Margarida }\end{array}$ & Autismo & $\begin{array}{c}8 \text { anos } \\
M\end{array}$ & $\begin{array}{c}\text { Associação de Pais e } \\
\text { Amigos dos Excepcionais }\end{array}$ & 5 anos \\
\hline $\begin{array}{c}\text { (E5) } \\
\text { Violeta }\end{array}$ & Autismo & $\begin{array}{c}5 \text { anos } \\
\mathrm{M}\end{array}$ & $\begin{array}{c}\text { Associação Terapêutica de } \\
\text { Estimulação Auditiva e } \\
\text { Linguagem }\end{array}$ & 2 anos \\
\hline (E6) Rosa & $\begin{array}{l}\text { Síndrome de } \\
\text { Asperger }\end{array}$ & $\begin{array}{l}10 \text { anos } \\
\mathrm{M}\end{array}$ & Psiquiatria privada & 2 anos \\
\hline $\begin{array}{l}\text { (E7) Flor } \\
\text { de Liz }\end{array}$ & $\begin{array}{l}\text { Síndrome de } \\
\text { Asperger }\end{array}$ & $\begin{array}{c}8 \text { anos } \\
M\end{array}$ & Psiquiatria privada & 1 ano \\
\hline
\end{tabular}




\section{- Diferença}

Este núcleo traz a percepção das mães sobre o início das alterações de comportamento de seus filhos, além do itinerário realizado desde a avaliação até o estabelecimento de tratamento específico para tais alterações

A diferença, no comportamento e relações interpessoais, é percebida pela maioria das mães, em comparação a outras crianças, e recorrente nos relatos:

...eu achei o comportamento dela diferente das outras crianças (...) por exemplo, o andar dela... ela andava, mas o andar dela pra subir uma escada era diferente das outras crianças né, e aquilo me chamou a atenção. (Camélia)

...a única coisa que chamava a atenção é que ele não falava, ele balbuciava muito (...) a pediatra falou que era normal, mas era uma coisa que já tava me incomodando (...) no ano seguinte o P. entrou na escolinha, e aí sim que deu pra ver a diferença gritante do comportamento do P. pro comportamento das outras crianças da idade dele . (Margarida)

A partir da percepção destas alterações, as mães iniciaram um longo, lento e sofrido itinerário para avaliação e posterior estabelecimento de um tratamento específico para os seus filhos; elas pontuam que este itinerário perpassa por vários lugares, exames e profissionais, que não se conversam e não se organizam como rede:

...daí encaminhou pro Centro de Reabilitação de (...) daí fez uma avaliação na APAE... daí ele já tava com 5 anos, que é tudo demorado né, as coisas, não é rápido assim como a gente quer... Daí passamos na APAE, avaliou, aí, demorou pra sair resultado, ele não colaborava, ele não conseguia ficar na sala... daí o Centro de Reabilitação encaminhou ele pra cá (CAPSi), aí aqui também fez muitas avaliações né, pra ver se era isso mesmo... (Azaleia)

... porque não tá certo se ele vai pra escola comum ou se ele vai pra APAE (...) eles são muito bagunçado, liga pra você, marca consulta, eles não fala se tem que levar o menino, chega lá não tem que trazer o menino, você tem que tá sempre perguntando (...) e não existe uma comunicação entre eles, mesmo sendo no mesmo prédio, mesmo sendo no mesmo local, o que eu respondi pra neuro, eu respondi pra psicóloga duas vezes, a mesma história... (Violeta)

... você não entender, não saber o que tá acontecendo com seu filho, chegou uma hora... parecia que não tinha nascido de mim "Não, não é meu filho, não é possível, acho que foi trocado na maternidade" sabe assim... (Azaleia)

(...) na primeira consulta, no consultório, ela (psiquiatra) já chegou pra mim e falou "Mãe, vamos pensar já num diagnóstico de autismo", o mundo caiu pra mim, voltei assim pra casa destruída, chorei a noite inteira, no outro dia não consegui ir trabalhar porque você pensa "Ai porque isso foi acontecer comigo?" (Margarida)

Outra percepção das mães sobre "Dificuldades" é em relação à inserção escolar de seus filhos, vista como consequência das alterações comportamentais. Relataram enquanto fatores dificultadores para tal inserção, questões relativas à inabilidade da escola e falta de conhecimento dos professores para receberem estas crianças; questões relativas à abordagem pedagógica específica; e, principalmente, a dificuldade para interação social apresentada por seus filhos:

... ele não conseguia ficar na classe, colocavam ele na diretoria pra carregar papel, então começaram a trabalhar com ele o que podiam fazer, porque também ninguém sabe o que fazer, ninguém sabe como lidar né! Parece assim que é vagabundice, sem-vergonhice, não fala que tem problema! (Azaleia)

... o pior momento foi o P. dentro da escolinha mesmo, normal, digo isso como mãe, a escolinha normal não tá preparada pra tal inclusão social (...) às vezes eu chegava lá o P. tava assim, num canto, parecia um animalzinho acuado com todo mundo em volta olhando assim, não sabiam o que fazer, e a professora chorando porque não sabia que atitude tomar com $o$ P. (Margarida)

\section{- Cuidado: sobrecarga versus proteção}

As mães relatam que o cuidado aos filhos é centrado em suas figuras, gerando uma sobrecarga por vários fatores - o itinerário intenso de tratamento dos filhos com TGD; o cuidado dos demais filhos e da casa; a ausência de auxílio geral pelo companheiro ou outro familiar.

Em geral, como cuidadoras principais, as mães acabam por viver o cotidiano dos filhos, anulando a si mesmas, em função de toda a demanda que uma criança com TGD exige:

Bom, pra mim, não existe mais o eu, existe o nós, enquanto você é solteira, só existe você, quando você vira mãe, é tudo nosso, é nosso pagamento, nosso passeio, nossa pizza... deixa de ser a pizza que você gosta pra ser a pizza que todo mundo curte... (Violeta) ...eu sei que eu abandonei meus dois filhos, eu abandonei meu marido, eu abandonei a casa pra cuidar do G. (Flor de Liz)

Outro ponto é a preocupação das mães em dedicarem-se a oferecer uma maior autonomia aos filhos, com vistas a preparálos para ter uma maior independência diante das necessidades de uma vida em sociedade. 
Entendem que a principal colaboração do CAPSi é a promoção de ações que invistam nessa independência, permitindo que tenham menor desgaste com as práticas de atividades diárias. Simultaneamente, surge outra preocupação, o medo da própria morte, considerando as dificuldades que seus filhos teriam em seguir uma vida sem a constante presença materna para amenizar ou protegêlos de quaisquer dificuldades:

... a minha preocupação também é assim, que eu morra hoje! Aí eu falo "Meu Deus, espera pelo menos o V. tá encaminhado" (...) então é uma preocupação, de morrer e deixar ele, porque ele é assim, não tem maldade nenhuma, malícia, é puro (...) sozinho eu não sei se ele sobreviveria. Eu sei que morrer a gente vai né, mas eu vou pedindo a Deus que por enquanto não, "Ai Senhor, não me leva ainda não, deixa eu cuidar dele!" (Azaleia)

... é que eu sei que não vou durar para sempre, eu e o meu marido, então eu tenho que deixar o P. preparado pra um dia ele poder se virar (...) então eu quero que um dia o P. possa viver bem, independente de ter uma família ou não, mas que ele não precise ter a mãe ou o pai pra sempre porque ele não vai ter (...) não precisa fazer a melhor faculdade, é só ele viver bem. (Margarida)

Comprei um cavalo pra ele fazer equoterapia (...) já fui atrás da Previdência dele, porque como eu não posso trabalhar eu não poderia deixar faltar nada pra ele... questão de convênio médico (...) que nem mudança, eu tô mudando de casa, então eu tô levando os móveis aos poucos, porque ele conhece aquela casa onde ele tá como casa, então tem que fazer aos poucos (...) porque se eu mudar de repente, vai chegar três horas da manhã, ele vai acordar querendo ir embora, então tem que ser aos poucos... (Violeta)

Eu já tô tomando providências, a gente morava num apartamento lá no condomínio... que é um espaço maior, tem parques, dá pra andar de bicicleta (...) então eu já tô me movendo pra me mudar pra lá de novo em dezembro nas férias dos meninos. (Flor de Liz)

As mães relatam que emerge uma forte tendência à estigmatização de seus filhos no espaço escolar, tanto pelos funcionários quanto pelos outros alunos e seus familiares. 0 preconceito em relação ao TGD é sentido pelas mães principalmente quando buscam uma escola para o filho e vivenciam situações de exclusão:

Agora esse ano a professora falou "Fulano e beltrano são bons, ele que às vezes fica de um jeito...", não sei, porque ninguém quer ter um filho aqui né (...) aí eu falei que é um pouco dele, um pouco é o que ele tem né, o quadro que ele tem... (Hortência)

É uma coisa que machuca qualquer mãe, é quando você vê que as outras crianças, as outras pessoas vão ser muito duras com o seu filho, eu cheguei a ouvir mãe na hora de eu ir buscar meu filho na porta da escola a falar assim "Tem certeza que aqui é o melhor lugar pro seu filho?" (...) sem contar as crianças que também judiavam dele, brigavam com ele e ele não tinha como se defender... (Margarida)

Por perceberem a fragilidade do filho diante do social, as mães também se sentem fragilizadas e isto as leva a protegerem ainda mais este filho, que para elas se coloca como uma criança indefesa; elas tomam para si praticamente todo este cuidado, tendo dificuldade para delegar a outras pessoas e aumentando sua sobrecarga frente ao filho:

... em qualquer lugar as pessoas falavam "Ai que menino sem educação", então hoje não, a gente foi aprendendo, e falar pras pessoas "Olha, ele é especial, é por isso que ele é assim", não, a gente tinha vergonha porque ele não é normal, mas depois que veio o tratamento você chega nas pessoas, falar a verdade foi melhor do que ficar escondendo. Não, eu não escondia, eu protegia sim... (Azaleia)

...e de repente alguém olha pro seu filho e fala que ele é diferente, e você começa a perceber que realmente é diferente... você não pensa em mais nada, só pensa no preconceito, mais nada. (Violeta)

As mães deste estudo, na tentativa de lidar com o luto pelo filho idealizado, buscam falas cercadas de um amor incondicional e pensamentos compensatórios, como a ideia de um cumprimento de uma missão:

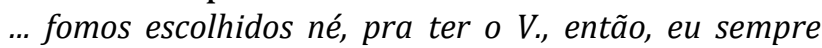
penso assim, de um milhão eu... de cada um milhão, uma criança é autista, então eu sou uma em um milhão... (Violeta)

Eu li a semana passada na Amarati um jornalzinho, uma das assistidas lá escreveu o que é ser especial "É um vento leve e forte" (...) mas eu acho que algum motivo tem, e a gente acaba descobrindo com o passar do tempo... o G. tá me ensinando muita coisa, a paciência que eu não tinha, a fé que antes de acontecer tudo isso também eu achei que não tivesse, a alegria que ele passa pra gente de viver(...) (Flor de Liz)

\section{DISCUSSÃO}

As alterações no comportamento das crianças, típicas da sintomatologia descrita no TGD como ausência de fala, isolamento social, atraso no desenvolvimento global, são percebidas a partir do segundo ano de vida (30 meses) e ao iniciarem a educação infantil ${ }^{12}$.

Conforme o relato das mães, os profissionais de saúde não usaram a característica do olhar do lactente como objeto significativo de avaliação, apesar de elas mesmas terem feito isso - ou seja, achavam o olhar "estranho". 
Apesar da complexidade que envolve o diagnostico dos TGDs, em parte pelas limitações nas avaliações da psiquiatria infantil2, também se viu nos relatos, que alguns profissionais não ofereceram escuta acolhedora para as mães, e deixam de realizar melhor anamnese desta criança e facilitar a observação de possíveis alterações, mesmo ocupando lugar privilegiado para tais intervenções. Tais ações poderiam fornecer subsídios para o cuidado dirigido a tal segmento populacional, visando integralidade e qualidade da assistência, baseando-se não somente nas necessidades especiais da criança, mas também nas necessidades e observações do seu cuidador ${ }^{13}$.

O momento do diagnóstico, ou a busca dele, é crucial para as mães, surgindo vários sentimentos - angústia, dúvidas, ansiedade, tristeza, culpa ${ }^{14}$. A falta de organização e comunicação entre os setores especializados no atendimento a essas crianças acaba por prorrogar o início do tratamento adequado, gerando ainda mais ansiedade para as mães acerca da situação em que seus filhos se encontram.

A integralidade em saúde como resultado de trabalho intersetorial permite o acesso ao cuidado equitativo. Nesta perspectiva, o acesso se relaciona à "habilidade diagnóstica" para organizar os encaminhamentos adequados para cada situação. As limitações e déficits presentes na atenção primária à saúde e a "falta de fluidez" no sistema de saúde como um todo são pontos de intervenção para tornar este processo menos tortuoso ${ }^{13,15}$.

Ao perceberem as alterações do filho e receberem uma hipótese diagnóstica de um TGD, as mães iniciam espontaneamente um processo de busca pela nomeação daquela estranha alteração que seu filho apresenta, demandando avaliações, diagnósticos e tratamentos, pois esperam que o filho seja curado16; este fato, acrescido à ausência de articulação entre os serviços que recebem essa demanda, torna esse processo ainda mais difícil e sofrido. Estudo demonstrou que alguns pais, pela ausência de informações nos serviços, buscam conhecimentos sobre a patologia dos filhos na Internet ${ }^{17}$. Neste momento, a criança idealizada se torna uma criança com TGD, e todas as expectativas que os pais colocavam sobre o filho se fragilizam; eles começam a perceber que não existirá uma cura para aquele problema que o filho apresenta e este filho real não corresponderá aos seus ideais. A mãe, por ser quem está mais próxima ao cuidado dos filhos, sente esta criança como desconhecida, surgindo dúvidas sobre como cuidar dela ${ }^{18}$.

Após esse contato inicial com um possível diagnóstico de TGD, as mães iniciam um processo de busca de elaboração e adaptação frente a esta nova situação. Neste momento, se coloca imprescindível um olhar especial a estas mães, através de ações para acolhimento deste sofrimento. Estudo indicou ainda que pais e crianças com transtornos mentais apresentam maior risco para ter necessidades de cuidado não atendidas, bem como dificuldades para acesso aos serviços ${ }^{19}$.

A interação social, de acordo com a literatura, se coloca como uma das três funções principais que estão perturbadas no TGD, sendo que as crianças têm dificuldade para exibir responsividade típica às emoções dos outros, o que sugere falências na função de interpretação e resposta a sinais de emoção, causando dificuldade nos relacionamentos ${ }^{19}$. Deste modo, o ambiente escolar é outra referência importante para os pais de crianças e adolescentes com TGD; após a busca incansável por tratamentos para o filho, surge também a necessidade e direito de integrá-lo à sociedade, e isto poderia ser favorecido pela entrada do filho na escola. Entretanto, esse momento acaba por ser gerador de crise, materializando "a questão da diferença e dos limites em relação à aprendizagem" 16 .

Ainda de acordo com as mães, a escola não se mostrou efetiva em atender as necessidades educacionais especiais das crianças com TGD. Este fato prejudica a criança não só em seu desenvolvimento cognitivo, mas também em seu desenvolvimento social ${ }^{20}$.

Ações intersetoriais envolvendo, de modo particular, as escolas como parceiras 
na identificação e prevenção de danos à saúde de crianças e adolescentes, uma vez que família e escola são indiscutivelmente os dois subsistemas mais relevantes na vida desses indivíduos, auxiliariam na melhoria do bem estar das crianças com TGD e de suas famílias ${ }^{21}$.

As cuidadoras se queixaram do desgaste pela convivência com a pessoa portadora de transtorno mental, acarretando sobrecarga física e emocional, privando-se da sua própria vida para poder prestar um cuidado adequado 22 .

As mães deparam-se com uma sobrecarga de tarefas e exigências especiais que podem suscitar situações potencialmente indutoras de estresse e tensão emocional ${ }^{15,19}$, As tarefas parentais não são compartilhadas de forma igualitária entre o casal; este fato não emerge de ações intencionais de uma das partes, mas em função das demandas próprias do TGD e da organização familiar para atender essas demandas ${ }^{23}$.

No que se refere às tarefas do pai, se observa a tendência de prestarem auxílio ocasional nas situações da vida diária, não assumindo tais tarefas de forma constante, sendo evidenciado que as mães são as principais responsáveis pelas atividades da vida diária do filho com TGD, cabendo-lhes a responsabilidade de auxiliar os filhos nas tarefas cotidianas como se alimentar, tomar banho, escovar os dentes, vestir-se e fazer higiene pessoal, além do acompanhamento aos serviços para tratamento 23 .

Outro aspecto é a alteração na dinâmica familiar e as mudanças na rotina devido ao funcionamento destas crianças e adolescentes. É importante compreender que o TGD implica mudanças familiares; adaptarse a tais mudanças e continuar a crescer buscando alternativas para transformações, isto é um processo que requer uma experiência construída, não é um aprendizado repentino; e é esse fator que, possivelmente, permite a estas mães se organizarem para o enfrentamento destas novas situações ${ }^{24}$.

Estas alterações e adaptações na dinâmica familiar são observadas como preocupações destas mães, em especial na estruturação financeira para promover uma garantia aos filhos, assim como em todas as escolhas de práticas cotidianas como, por exemplo, a disposição dos móveis da casa, a compra de determinados itens para os estímulos de aprendizado ou simplesmente para evitar desgastes com reações exageradas devido à própria singularidade da criança ou adolescente.

A preocupação com os irmãos destes indivíduos é outra questão importante, pois vivem intensamente as complexas relações fraternas, e tem suas rotinas individuais e familiares alteradas, geralmente em função do irmão com TGD ${ }^{25}$. Indica-se o uso de estratégias para planejar os cuidados futuros como: providenciar tutela, fazer poupança e planos de saúde, conhecer os direitos dos portadores e buscar recursos na comunidade ${ }^{26}$.

As considerações a respeito de falas de terceiros envolvidos nos ambientes em que as crianças participam, mostram que as mães se preocupam demasiadamente com a visão dos outros; elas percebem este preconceito e estigmatização como dirigidos a elas mesmas. O olhar do outro é mais um fator que influencia na vivência da maternidade - ver que as pessoas ficam incomodadas com a presença de seus filhos é sentido pelas mães como um gesto de preconceito contra si mesmas $^{16}$.

Estudo corroborou este achado, quando as mães preocuparam-se demasiadamente em proteger seus filhos, com intervenções desnecessárias ou frequentes repressões, diminuindo suas oportunidades de comportamento exploratório e experimentação do mundo externo ${ }^{27}$.

Recente estudo que investigou a associação entre a qualidade de vida e sintomas depressivos em mães de indivíduos com TGD, demonstrou maiores sintomas depressivos e menor qualidade de vida entre estas mães. Alem disso, a menor satisfação com o domínio ambiente como o acesso ao cuidado em saúde, à informação, à moradia, à oportunidade de lazer, à recreação, à interação social, ao transporte, foi identificado entre estas cuidadoras ${ }^{28}$. 
Estudos reforçam a demanda por intervenções preventivas e terapêuticas, visto que a interação e estímulos maternos são importantes para o desenvolvimento infantil saudável, assim como, o melhor bem estar de crianças e adolescentes em sofrimento mental ${ }^{27,29}$.

\section{CONCLUSÃO}

Acerca das percepções das mães sobre o cuidado e as demandas de cuidado do filho com TGD, verifica-se a diferença percebida quando comparam seus filhos a outras crianças, principalmente, ao iniciarem a educação infantil e, no âmbito da interação social.

Nas demandas de cuidado, uma sobrecarga de cuidados aos filhos, acrescida de outras funções enquanto mãe e mulher; sentem que seus filhos são estigmatizados principalmente no ambiente escolar, e remetem esse preconceito a si mesmas, além de perceberem esse filho como frágil e reforçarem a necessidade de proteção sobre eles. Trazem como atitudes de enfrentamento atuais, pensamentos, ideias compensatórias e de cumprimento de uma missão.

As ações dirigidas a mães de crianças e adolescentes com TGD se colocam como emergentes para que exista um enfrentamento eficaz das situações vivenciadas, principalmente na organização do processo de avaliação dos transtornos mentais, no momento da elucidação diagnóstica e no processo de adaptação pessoal e social frente às alterações específicas apresentadas. Além deste aspecto, denota-se a necessidade de um trabalho intersetorial junto a estas famílias, o que ainda se apresenta como um desafio.

0 enfermeiro, como importante ator social envolvido nesse contexto, precisa se apresentar ativamente nas discussões sobre o preconceito e a sobrecarga física e emocional que atingem mães de filhos com TGD, se apropriando de novos conhecimentos e habilidades que subsidiem e aprimorem sua prática.

Novos estudos que busquem lançar luz sobre a saúde mental infanto-juvenil, sob a ótica de outros atores e em outros serviços/setores dedicados ao cuidado de crianças e adolescentes, são necessários para a complementação dos achados deste trabalho.

\section{REFERÊNCIAS}

1. Milbrath VM, Cecagno D, Soares DC, Amestoy SC, Siqueira HCH. Ser mulher mãe de uma criança portadora de paralisia cerebral. Acta Paul Enferm. 2008; 21(3):427-31.

2. Vicente JB, Higarashi IH, Furtado MCC. Transtorno mental na infância: configurações familiares e suas relações sociais. Esc Anna Nery. Rev Enferm. 2015; 19(1):107-14.

3. Falkenbach AP, Drexler G, Werler V. A relação mãe/criança com deficiência: sentimentos e experiências. Ciênc Saúde Coletiva. 2008; 13(2):2065-73.

4. Jerusalinsky J, Freire AB, Jerusalinsky A, Mascarenhas C, Teperman D, Telles HP, et al. Autismos e seus tratamentos: contribuições da metodologia psicanalítica nesse campo. Correio APPOA. 2013; 222/223:25-45.

5. Semensato MR, Bosa CA. A família das crianças com autismo: contribuições empíricas e clínicas. In: Schmidt, C (Org.). Autismo, educação e transdisciplinariedade. Campinas: Papirus; 2013. p. 81-103.

6. Monteiro CFS, Batista DONM, Moraes EGC, Magalhães TS, Nunes BMVT, Moura MEB. Vivências maternas na realidade de ter um filho autista: uma compreensão pela enfermagem. Rev Bras Enferm. 2008; 61(3):330-5.

7. Araújo YB, Reichert APS, Oliveira BRG, Collet N. Rede e apoio social de famílias de crianças com doença crônica: revisão integrativa. Ciênc Cuid Saúde. 2011; 10(4):853-60.

8. Araújo YB, Reichert APS, Vasconcelos MGL, Collet N. Fragilidade da rede social de famílias de crianças com doença crônica. Rev Bras Enferm. 2013; 66(5):675-81.

9. Nóbrega VM, Reichert APS, Silva KL, Coutinho SED, Collet N. Imposições e conflitos no cotidiano das famílias de crianças com doença crônica. Esc Anna Nery Rev Enferm. 2012; 16(4):781-8.

10. Sena RCF, Reinalde EM, Silva GWS, Sobreira MVS. Prática e conhecimento dos enfermeiros sobre o autismo infantil. Rev Pesqui Cuid Fundam (Online). 2015 [citado em 25 ago 2015]; 7(3):2707$16 . \quad$ Disponível em: http://www.seer.unirio.br/index.php/cuidadofund amental/article/view/3883/pdf_1609.

11. Bardin L. Análise de conteúdo. Edição revista e ampliada. Lisboa: Edições 70; 2011.

12. Tamanaha AC, Perissinoto J, Chiari BM. Uma breve revisão histórica sobre a construção dos conceitos do Autismo Infantil e da Síndrome de 
Asperger. Rev Soc Bras Fonoaudiol. 2008; 13(3):296-9.

13. Nehmy RMQ, Brito AC, Mota JAC, Oliveira BM. A perspectiva dos pais sobre a obtenção do diagnóstico de leucemia linfoide aguda em crianças e adolescentes: uma experiência no Brasil. Rev Bras Saúde Mater Infant. [Internet]. 2011 [Citado em 22 abr 2012]; 11(3):293-99. Disponível em: http://www.scielo.br/pdf/rbsmi/v11n3/a10v11n3 .pdf.

14. Souza LGA, Boemer MR. O ser-com o filho com deficiência mental: alguns desvelamentos. Paidéia. 2003; 13(26):209-19.

15. Gomes PTM, Lima LHL, Bueno MKG, Araújo LA, Souza NM. Autism in Brazil: a systematic review of family challenges and coping strategies. J Pediatr. 2015; 91(2):111-21.

16. Smeha LN, Cezar PK. A vivência da maternidade de mães de crianças com autismo. Psicol Estud. 2011; 16(1):43-50.

17. Lima RC, Couto MCV, Delgado PGG, Oliveira BDC. Indicadores sobre $o$ cuidado a crianças $\mathrm{e}$ adolescentes com autismo na rede de CAPSi da região metropolitana do Rio de Janeiro. Physis. 2014; 24(3):715-39.

18. Brown NM, Green JC, Desai MM, Weitzman CC, Rosenthal MS. Need and Unmet Need for Care Coordination Among Children With Mental Health Conditions. Pediatrics. 2014; 133(3):530-7.

19. Fávero MAB, Santos MA. Autismo infantil e estresse familiar: uma revisão sistemática da literatura. Psicol Reflex Crit. 2005; 18(3):358-69.

20. Falavina OP, Cerqueira MB. Saúde mental infanto-juvenil: usuários e suas trajetórias de acesso aos serviços de saúde. Espaç Saúde. 2008; 10(1):34-46.

21. Zavaschi MLS. Crianças e adolescentes vulneráveis: o atendimento interdisciplinar nos centros de atenção psicossocial. Porto Alegre: Artmed; 2009. 22. Navarini V, Hirdes A. A família do portador de transtorno mental: identificando recursos adaptativos. Texto \& Contexto Enferm. 2008; 17(4):680-8.

23. Sifuentes M, Bosa CA. Criando pré-escolares com autismo: características e desafios da coparentalidade. Psicol Estud. 2010; 15(3):477-85.

24. Marques MH, Dixe MAR. Crianças e jovens autistas: impacto na dinâmica familiar e pessoal de seus pais. Rev Psiquiatr Clín. 2011; 38(2):66-70.

25. Cezar PK, Smeha LN. Repercussões do autismo no subsistema fraterno na perspectiva de irmãos adultos. Estud Psicol. 2016; 33(1):51-60.

26. Schmidt C, Dell'Aglio DD, Bosa CA. Estratégias de Coping de mães de portadores de autismo: lidando com dificuldades e com a emoção. Psicol Reflex Crit. 2007; 20(1):124-31.

27. Ribeiro DG, Perosa GB, Padovani FHP. Mental health, mother-child interaction and development at the end of the first year of life. Paidéia. 2014; 24(59):331-9.

28. Piovesan J, Scortegagna AS, Marchi ACB. Quality of life and depressive symptomatology in mothers of individuals with autism. Psico-USF. 2015; 20(3):505-15.

29. Egeland B. Programas de intervenção e prevenção para crianças pequenas baseados no apego. In: Tremblay RE, Boivin $M$, Peters RDeV, editores. Enciclopédia sobre o Desenvolvimento na Primeira Infância [Internet]. Montreal, Quebec: Centre of Excellence for Early Childhood Development; 2011 [citado em jan 2016]. p. 1-8. Disponível em: http://www.enciclopediacrianca.com/documents/EgelandPRTxp1.pdf.

CONTRIBUIÇÕES
Chalimar da Cunha foi responsável pela concepção
e delineamento metodológico do estudo, coleta,
discussão e análise dos dados. Raquel Godinho
Hokama Santos contribuiu na análise dos dados e
revisão crítica. Diene Monique Carlos foi
responsável pela orientação da concepção e
delineamento do estudo, discussão e análise dados,
e revisão crítica.

\footnotetext{
Como citar este artigo (Vancouver):

Cunha C, Santos RGH, Carlos DM. O filho com transtorno global do desenvolvimento: percepções de mães acerca de cuidados cotidianos. REFACS [Online]. 2016 [citado em (inserir dia, mês e ano de acesso)]; 4(2). Disponível em: (link de acesso). DOI: 10.18554/refacs.v4i2.1646.

Como citar este artigo (ABNT):

CUNHA, C.; SANTOS, R. G. H.; CARLOS, D. M. O filho com transtorno global do desenvolvimento: percepções de mães acerca de cuidados cotidianos. REFACS, Uberaba, MG, v. 4, n. 2, p. 98-106, 2016. Disponível em: (link de acesso). DOI: 10.18554/refacs.v4i2.1646. Acesso em: (inserir dia, mês e ano de acesso).

Como citar este artigo (APA):

Cunha, C., Santos, R. G. H. \& Carlos, D. M. (2016). O filho com transtorno global do desenvolvimento: percepções de mães acerca de cuidados cotidianos. REFACS, 4(2), 98-106. Recuperado em: (dia), (mês), (ano) de (link de acesso). DOI: 10.18554/refacs.v4i2.1646.
} 